\title{
KAITAN KINERJA PERAWAT DALAM MENERAPKAN PROSES KEPERAWATAN DI RUMAH SAKIT
}

\author{
Elsya Fitri Syofian \\ elsyafitrisyofian93@gmail.com
}

\begin{abstract}
ABSTRAK
Proses keperawatan merupakan aktivitas yang mempunyai maksud yaitu praktik keperawatan yang dilakukan dengan cara yang sistematik. Perawat memiliki beberapa standar asuhan yang tercantum dalam Standar Praktik Klinis Keperawatan terdiri dari lima fase asuhan keperawatan: 1) Pengkajian; 2) Diagnosa; 3) Perencanaan; 4) Implementasi; dan 5) Evaluasi. Kinerja perawat yang baik dalam menerapkan proses keperawatan di rumah sakit akan berdampak pada peningkatan mutu serta kepuasan pasien. Dari hasil yang didapat terdapat beberapa faktor yang mempengaruhi kinerja perawat seperti usia, masa kerja, dan tingkat pendidikan. Disamping itu kinerja perawat yang kurang baik dalam menerapkan proses keperawatan di rumah sakit yaitu kurang memerhatikan pengisian dalam tahapan proses keperawatan dimulai dari pengkajian sampai evaluasi.
\end{abstract}

Kata kunci: Proses Keperawatan, Kinerja Perawat

\section{Latar Belakang}

Tenaga perawat yang merupakan "The caring profession" mempunyai kedudukan penting dalam menghasilkan kualitas pelayanan kesehatan di rumah sakit, karena pelayanan yang diberikannya berdasarkan pendekatan bio-psikososialspiritual merupakan pelayanan yang dilaksanakan selama 24 jam dan berkesinambungan merupakan kelebihan tersendiri dibanding pelayanan lainnya. Perawat merupakan salah satu tenaga medis di rumah sakit yang memberikan pelayanan untuk menunjang kesembuhan pasien, oleh sebab itu peran perawat di rumah sakit sangatlah dibutuhkan. Salah satu indikator 
dari peran perawat di rumah sakit yaitu 3 perawat melakukan suatu pengkajian dan memberikan rasa aman dan nyaman kepada individu yang mengalami sakit (Sarnita,2014).

Rumah sakit merupakan sebuah organisasi kesehatan yang sangat bermanfaat guna memberikan pelayanan kesehatan bagi masyarakat, sebagaimana tertera dalam UU RI No 44 pasal 1 (2009, p.2). Setiap tenaga kesehatan yang bekerja dirumah sakit harus bekerja sesuai dengan standar profesi, standar pelayanan rumah sakit, standar prosedur operasional yang berlaku, etika profesi, menghormati hak pasien, dan mengutamakan keselamatan pasien. Tenaga kesehatan tersebut diantaranya tenaga medis dan penunjang medis, tenaga keperawatan, tenaga kefarmasian, tenaga manajemen rumah sakit dan tenaga non kesehatan UU RI No 44 pasal 12-13 (2009, p.11-12). Salah satu pelayanan kesehatan yang diberikan oleh tenaga kesehatan adalah pelayanan keperawatan, Sebagai bagian dari pelayanan kesehatan, maka pelayanan keperawatan yang dilakukan oleh tenaga perawatmemiliki tugas diataranya memberikan asuhan keperawatan (Hidayat, 2011, p.75).

Dalam memberikan asuhan keperawatan, perawat memiliki beberapa standar asuhan yang tercantum dalam Standar Praktik Klinis Keperawatan terdiri dari lima fase asuhan keperawatan: 1) Pengkajian; 2) Diagnosa; 3) Perencanaan; 4) Implementasi; dan 5) Evaluasi. Salah satu manfaat dari penerapan asuhan keperawatan yang baik adalah meningkatkan mutu dan kualitas pelayanan dalam bidang keperawatan (Kozier, 2010).

Dalam hal ini kinerja perawat berpengaruh dalam menerapkan proses keperawatan untuk meningkatkan mutu kualitas dalam pelayanan keperawatan di rumah sakit. Apabila perawat memiliki kinerja yang baik dalam memberikan asuhan keperawatan dan menerapkan proses keperawatan, maka akan dapat meningkatkan mutu dan membeikan kepuasan pada pasien, keluarga serta orang yang berkunjung ke rumah sakit.

\section{Metode}

Metode yang digunakan adalah metode kualitatif. Metode yang berlandaskan teori dari buku, koran, majalah, jurnal, serta e-book yang memuat segala informasi mengenai kinerja perawat dalam menerapkan proses keperawatan di rumah sakit. Dengan mengumpulkan beberapa sumber, dapat dianalisa bagaimana 
kinerja perawat dalam menerapkan proses keperawatan di rumah sakit.

\section{Hasil}

Dalam menjalankan asuhan keperawatan di rumah sakit perawat memiliki standar praktik keperawatan yang terdapat dalam proses keperawatan yang meliputi pengkajian, diagnose keperawatan, perencanaan keperawatan, implementasi, dan evaluasi. Proses keperawatan merupakan aktivitas yang mempunyai maksud yaitu praktik keperawatan yang dilakukan dengan cara yang sistematik. Selama melaksanakan proses keperawatan, perawat menggunakan dasar pengetahuan yang komprehensif untuk mengkaji status kesehatan klien, membuat penilaian yang bijaksana dan mendiagnosa, mengidentifikasi hasil akhir kesehatan klien dan merencanakan, menerapkan dan mengevaluasi tindakan keperawatan yang tepat demi meningkatkan mutu serta kualitas pelayanan.

Kinerja perawat yang baik dalam menerapkan proses keperawatan di rumah sakit akan berdampak pada peningkatan mutu serta kepuasan pasien. Dari hasil yang didapat terdapat beberapa faktor yang mempengaruhi kinerja perawat seperti usia, masa kerja, dan tingkat pendidikan.

Perawat yang memberikan asuhan keperawatan pada umur 30-34 tahun mereka berada pada usia produktif dan telah memilih pekerjaan yang sesuai karirnya bahkan semakin memantapkan pekerjaannya untuk mencapai tujuan. Disamping itu kinerja para perawat pelaksana sudah berpengalaman menjalankan profesinya karena memiliki masa kerjanya minimal 1 sampai dengan 23 tahun. Mereka sudah menerapkan proses keperawatan sesuai dengan standar asuhan keperawatan yang telah ditetapkan. Kinerja perawat dalam penerapan proses keperawatan juga merupakan aplikasi kemampuan atau pembelajaran yang diterima selama menyelesaikan program pendidikan keperawatan untuk memberikan pelayanan kesehatan secara langsung kepada pasien.

Kinerja perawat yang kurang baik dalam menerapkan proses keperawatan di rumah sakit akan berdampak pada kepuasan pasien. Hal-hal yang menyebabkan proses keperawatan belum berjalan dengan baik yaitu seperti kurang lengkapnya pengisian status pasien, merumuskan diagnose keperawatan yang kurang benar, antara masalah dan etiologinya, tidak semua 
perawat menentukan rencana keperawatan, tidak melakukan pengawasan lebih lanjut pasca tindakan, serta perawat tidak melakukan pencatatan hasil evaluasi sehingga kurang mampu untuk mendukung dalam merumuskan masalah.

\section{Pembahasan}

Rumah sakit merupakan salah satu sarana pelayanan kesehatan bagi klien sehat atau sakit yang membutuhkan bantuan pelayanan dari tim kesehatan termasuk perawat. Tenaga keperawatan merupakan anggota tim kesehatan garda depan yang menghadap imasalah kesehatan klien selama 24 jam secara terus menerus. Tim keperawatan memberikan pelayanan asuhan keperawatan kepada klien menggunakan metode proses keperawatan dengan mengacu pada kode etik dan standar praktek yang ditetapkan. Hal ini dimaksudkan agar pelayanan keperawatan yang diberikan senantiasa aman dan dapat memenuhi kebutuhan serta harapan klien.

Pelayanan keperawatan merupakan pelayanan profesional, sebagai bagian integral dari pelayanan kesehatan yang mempunyai daya ungkit besar terhadap pembangunan bidang kesehatan. Kualitas pelayanan kesehatan ditentukan salah satunya dari kualitas pelayanan keperawatan yang diberikan oleh perawat yang berkualitas (PPNI, 2016).

Dalam memberikan $r$ asuhan
keperawatan, perawat memiliki standar
asuhan keperawatan yaitu dengan adanya
proses keperawatan. Standar asuhan
keperawatan berfungsi sebagai pedoman
maupun tolak ukur dalam pelaksanaan
praktek keperawatan agar sesuai dengan
nilai-nilai profesional, etika dan tanggung
jawab. (Anwar, 1980).

Proses keperawatan adalah metode asuhan keperawatan yang digunakan perawat sebagai metode pemecahan masalah klien yang bersifat ilmiah dan merupakan serangkaian tindakan untuk mengkaji dan mengidentifikasi masalah kesehatan menetapkan diagnose keperawatan, merencanakan secara sistimatis, melaksanakan tindakan keperawatan untuk membantu klien mencapai kesehatan yang optimal dan mengevaluasi hasil tindakan keperawatan (Ann Marriner). Proses keperawatan harus diterapkan secara berurutan, terus menerus, saling berkaitan dan dinamis (Wolf \& Weitzel).

Adapun tujuan proses keperawatan menurut Manurung (2011) yaitu: 
a. Mempraktikkan metode pemecahan masalah dalam praktik keperawatan.

b. Menggunakan standar untuk praktik keperawatan.

c. Memperoleh metoda yang baku dan sesuai, rational dan sistematis dalam memberikan asuhan keperawatan pada pasien.

d. Memperoleh metoda yang dapat digunakan dalam segala situasi.

e. Memperoleh hasil asuhan keperawatan dengan kualitas tinggi.

Dalam memberikan asuhan keperawatan kepada pasien, kinerja perawat dapat berpengaruh dalam menerapkan proses keperawatan. Kinerja perawat dapat dilihat sesuai dengan peran fungsi perawat sebagai pemberi asuhan keperawatan. Hal ini didukung oleh standar praktek keperawatan Undang-Undang No 38 Tahun 2014 dan peraturan tentang kewewenang praktek perawat oleh kepmenkes RI no 1239 tahun 2001 dan permenkes RI No 148 tahun 2010 yaitu kinerja perawat ditinjau dari pelaksanaan asuhan keperawatan yang meliputi pengkajian, diagnosa, intervensi, implentasi dan evaluasi.

Standar praktik keperawatan yang mengacu dalam tahapan proses keperawatan yang meliputi: (1) Pengkajian, (2) Diagnosis keperawatan, (3) Perencanaan,

Implementasi, (5) Evaluasi.

- Standar I: Pengkajian: Perawat mengumpulkan data tentang status kesehatan klien secara sistematis, menyeluruh, akurat, singkat, dan berkesinambungan. Kriterianya:

a) Pengumpulan data dilakukan dengan cara anamnesis, observasi, pemeriksaan fisik, serta dari pemeriksaan penunjang,

b) Menggunakan metode penggumpulan data yang tepat,

c) Sumber data adalah klien, keluarga, atau oarng yang terkait, tim kesehatan, rekam medis, dan catatan lain, dan

d) Data yang dikumpulkan (subjektif dan objektif), difokuskan untuk mengidentifikasi: status kesehatan masalalu dan saat ini, status biologis, psikologis, sosial, spiritual, respons terhadap terapi, harapan terhadap tingkat kesehatan yang optimal, resikoresiko tinggi masalah

- Standar II: Diagnosa Keperawatan, dengan kriteria: 
a) Proses diagnosis terdiri atas analisis, interprestasi data, identifikasi masalah klien, dan perumusa diagnosis keperawatan,

b) Diagnosis keperawatan terdiri atas masalah $(\mathrm{P})$, penyebab $(\mathrm{E})$, dan tanda atau gejala (S), atau terdiri atas masalah penyebab $(\mathrm{PE})$,

c) Bekerjasama dengan klien, dan petugas kesehatan lain untuk mengvalidasi diagnosis keperawatan dan

d) Membuat prioritas diagnose dan mencatat denganbenar.

- Standar III: Perencanaan Keperawatan, kriteria proses:

a) Perencanaan terdiri atas penetapan prioritas masalah, tujuan, dan rencana tindakan keperawatan,

b) Bekerjasama dengan klien dalam menyusun rencana tinndakan keperawatan,

c) Perencanaan bersifat individual sesuai dengan kondisi atau kebutuhan klien, dan

d) Mendokumentasikan rencana keperawatan

- Standar IV: Implementasi, kriteria proses: a) Bekerjasama dengan klien dalam pelaksanaan tindakan keperawatan,

b) Melakukan kolaborasi dengan tim kesehatan lain,

c) Melakukan tindakan keperawatan untuk mengatasi kesehatan klien,

d) Memberikan pendidikan pada klien dan keluarga mengenai konsep, keterampilan asuhan diri serta membantu klien memodifikasikan lingkungan yang digunakan, dan

e) Mengkaji ulang dan merevisi pelaksanaan tindakan keperawatan berdasarkan respons klien

- Standar V: Evaluasi keperawatan, kriteria proses:

a) Menyusun perencanaan evaluasi hasil dari intervensi secara komperhensif, tepat waktu, dan terus menerus,

b) Menggunakan data dasar dan respons klien dalam mengukur perkembangan kearah pencapaian tujuan,

c) Memvalidasi dan menganalisis data baru dengan teman sejawat, 
d) Bekerjasama dengan klien, keluarga untuk memodifikasikan rencana asuhan keperawatan, dan

e) Mendokumentasikan hasil evaluasi dan memodifikasi perencanaan (Nursalam 2009).

Perawat perlu menerapkan proses keperawatan dalam memberikan pelayanan keperawatan di rumah sakit agar dapat meningkatkan mutu dan kualitas pelayanan. Peningkatan mutu pelayanan keperawatan diberikan dalam bentuk kinerja perawat dan harus didasari kemampuan yang tinggi sehingga kinerja mendukung pelaksanaan tugas dalam pelayanan keperawatan. Kinerja merupakan suatu hasil kerja seseorang yang dilakukan sesuai dengan tugas dalam suatu organisasi (Nursalam, 2014) .

\section{Kinerja perawat pelaksana} merupakan hal yang tidak terpisahkan dari indicator mutu pelayanan keperawatan dan serta kepuasan pasien yang bermuara pada pelayanan asuhan keperawatan yang berkualitas berdasarkan kinerja perawat yang profesional. Tetapi masih ditemui kinerja perawat dalam menerapakan proses keperawatan belum optimal. Sehingga berdampak pada pemberian pelayanan kesehatan yang tidak professional juga.
Kinerja perawat pelaksana yang kurang baik dikarenakan penerapan asuhan keperawatan yang belum optimal. Seperti berkas pasien yang tidak terisi lengkap, saat pengkajian tidak dilakukan secara head to toe, dan pengkajian psiko social serta budaya. Dalam menentukan diagnose keperawatan perawat pelaksana lebih banyak bersifat actual daripada potensil. Kemudian tidak semua perawat menentukan rencana keperawatan. Hal ini karena untuk membuat rencana keperawatan memerlukan waktu, disatu sisi perawat harus memberikan pelayanan keperawatan secara cepat. Pada tahap implementasi masih ada perawat yang kurang memperhatikan respon pasien, terkadang tidak melakukan pengawasan lebih lanjut pasca tindakan. Selain itu pada tahap evaluasi kebanyakan perawat tidak melakukan pencatatan hasil evaluasi, pencatatan tidak dilakukan secara lengkap sesuai dengan tindakan yang telah dilaksanakan serta pencatatan dilakukan kurang jelas dan sangat ringkas.

Kinerja perawat juga dipengaruhi oleh beberapa faktor, seperti usia, masa kerja, serta tingkat pendidikan. Jika kinerja perawat pelaksana dalam menerapkan proses keperawatan di rumah sakit dilaksanakan dengan baik, maka akan dapat mencapai hasil untuk meningkatkan mutu dan kualitas 
pelayanan yang akan berdampak pada kepuasan pasien.

\section{Penutup}

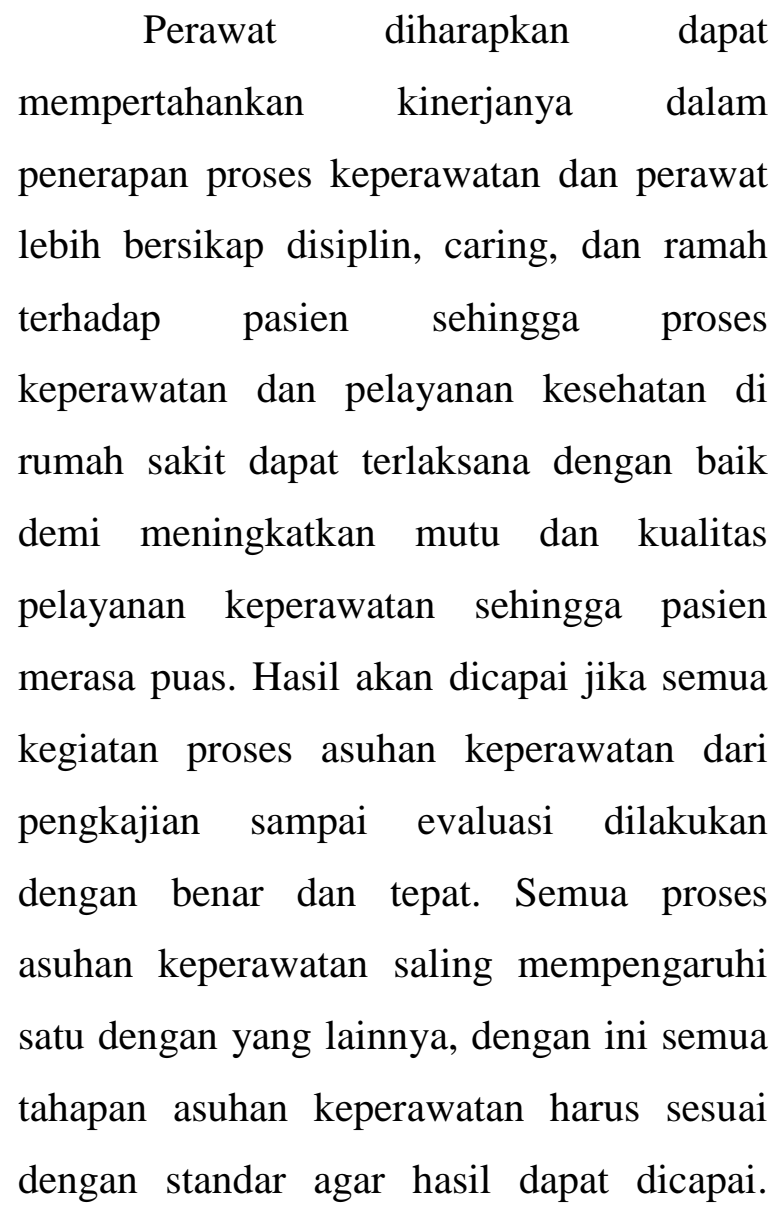




\section{Daftar Pustaka}

Buheli, K. (2012). Faktor yang Mempengaruhi Kinerja Perawat dalam

Penerapan Proses Keperawatan di RSUD Toto Kabupaten Bone Bolango. Jurnal Sainstek, 6(5).

Koerniawan, D., Daeli, N. E., \& Srimiyati. (2020). Aplikasi Standar Proses Keperawatan: Diagnosis, Outcome, dan Intervensi Pada Asuhan Keperawatan. Jurnal Keperawatan Silampari, 3(2), 739751.

Muhith, A. (2015). Pendidikan Keperawatan Jiwa Teori dan Aplikasi. Yogyakarta: Andi.

Najibullah, M., \& Milkhatun. (2020). Hubungan Antara Pelatihan Proses Keperawatan dengan Motivasi Perawat Tentang Penerapan Standar Diagnosis Keperawatan Indonesia di Rumah Sakit Umum Daerah Pemerintah Samarinda. Borneo Student Research, 1(3), 1836-1867.

Oxyandi, M., \& Suherwin. (2018). Analisis Kinerja Perawat Pelaksana dalam Pemberian Asuhan Keperawatan di Instalasi Rawat Inap Tahun 2018. Jurnal 'Aisyiyah Medika, 2, 140-152.

Salim, A. (2020). Faktor-faktor yang Berhubungan dengan Kelengkapan
Dokumentasi Pengkajian Rawat Jalan di Rumah Sakit Awal Bros Batam Tahun 2016. Journal of Hospital Administration and Management, 1(1), 1-9.

Sari, F. Y. (2019). Analisis Penerapan Proses Asuhan Keperawatan Terkait Manajemen Nyeri Terhadap Kepuasan Pasien di Rumah Sakit Universitas Tanjungpura. Jurnal Proners, 4(1), 2-12.

Simamora, R. H. (2008). The correlation of ward chief's giving direction and command and the performance of on-duty nurses at Jember dr. Subandi general hospital inpatient wards. Jurnal Administrasi dan Kebijakan Kesehatan.

Simamora, R. H. (2019). Development of Guidelines for Applying appropriate Patient Identification to Achieve Patient Safety Goal INC2019 12th International Nursing Conference. 2019.10455 - 455 (1 pages) UCI(KEPA) : I410-ECN-0101-2019-512001224337

Siswanto, L. M. H., Hariyati, Rr. T. S., \& Sukihananto. (2013). Faktor-faktor yang Berhubungan dengan Kelengkapan Pendokumentasian Asuhan Keperawatan. 
Jurnal Keperawatan Indonesia, 16(2), 77-

84.

Terok, M., Sumarauw, H., \& Onseng, S. L.

(2015). Hubungan Kinerja Perawat

Pelaksana dengan Penerapan Proses

Keperawatan di Irina C Blu RSUP Prof. DR.

R. D. Kandou Manado. Juiperdo, 4(1), 55-

62.

Yeni, F. (2014). Pengaruh Pelatihan Proses

Keperawatan terhadap Dokumentasi Asuhan

Keperawatan di Puskesmas Kabupaten Agam Propinsi Sumatera Barat. Ners Jurnal

Keperawatan, 10(1), 21-27. 